\title{
Biomass waste-derived activated carbon for the removal of arsenic and manganese ions from aqueous solutions
}

\author{
T. Budinova ${ }^{1}$, D. Savova ${ }^{1}$, B.Tsyntsarski ${ }^{1}$, C.O. Ania ${ }^{2}$, B. Cabal $^{2}$, J.B. Parra ${ }^{2}$, N. \\ Petrov $^{1}$ \\ ${ }^{1}$ Laboratory of Solid Fuels, Institute of Organic Chemistry, Bulgarian Academy of \\ Sciences, 1113 Sofia, Bulgaria \\ ${ }^{2}$ Instituto Nacional del Carbon, CSIC, Apartado 73, 33080, Oviedo, Spain
}

\begin{abstract}
The goal of this study was to investigate the preparation of low-cost activated carbons from bean pods waste and to explore their potential application to the removal of heavy metals from aqueous solutions. Conventional physical (water vapor) activation was used for synthesizing the adsorbent. The obtained carbon was employed for the removal of As (III) and Mn (II) from aqueous solutions at different initial concentrations and $\mathrm{pH}$ values. Adsorption for both ions follows Langmuir-type isotherm, the maximum loading capacities for arsenic (III) and Mn (II) ions being 1.01 and $23.4 \mathrm{mg} \mathrm{g}^{-1}$, respectively. According to the experimental data, it can be inferred that the basic character of the surface, i.e. the high content of basic groups favors adsorption of ions. Arsenic adsorption capacity on the carbon obtained from agricultural waste was found to be similar to more expensive commercial carbons showing high adsorption capability. As regards manganese adsorption, herein obtained carbon presented higher uptake than that of activated carbons reported in the literature.
\end{abstract}

Key words: activated carbon, bean pods, adsorption, arsenic, manganese.

*To whom all correspondence should be sent:

E-mail:goriva@orgchm.bas.bg Fax: 00359-2-870-02-25,

Present address: Inst. of Organic Chemistry. Bulgarian Academy of Sciences,

Acad.G.Bonchev 9, str., 1113, Sofia, Bulgaria 


\section{Introduction.}

Most adverse aspect of global industrialization of the countries is the negative environmental impact. The many technological developments occurred in the last years are leading to a gradual economic growth of the countries, but at the same time cause serious environmental risks and damages. Large concentrations of toxic pollutants appear frequently in drinking water and wastewater posing an important environmental issue, particularly in densely populated cities where the demand for water is very high. The amount and variety of toxic substances thrown into water resources- including for instance phenols, pesticides, aliphatic and aromatic hydrocarbons, dyes, surfactants, or heavy metals- due to human and industrial actives has rapidly for the last years. Moreover, noxious impact of these compounds in the environment and human health is not well known yet $[1,2]$.

Heavy metals are continuously released into aquatic environment from natural processes such as volcanic activity and weathering of rocks. Both arsenic and manganese are highly toxic elements which can be found naturally occurring in the environment, as well as introduced contaminants (industrial pollution). The industrial activities responsible for the environmental dispersion of arsenic are the agricultural use of arsenic as pesticides, herbicides and fertilizers, the discharges from coal fired in thermal power plants, petroleum refining industry, ceramic industries, and so forth. On the other hand, mining industry, ore-concentration factories and flotation of various non-ferrous metals are the main sources for manganese anthropogenic pollution.

Adsorption has become a well-established technique to remove pollutants, being activated carbon the prevailing adsorbent for the purification of water with low pollutant 
concentration. The major drawbacks are a poor economic feasibility, limited applicability and effectiveness, and a short lifetime often due to low and expensive regeneration capacities. Generally, the loaded carbon is regenerated ex-situ by heating or steaming, which is a high energy-consuming process, a costly procedure and, although the efficiency is relatively high, there is a considerable loss of activated carbon [3].

Summarizing, commercially available carbons are expensive, therefore more efficient and low cost alternatives to current technologies and materials in the water sector must be applied. An alternative is to use a low cost adsorbent that does not represent an economic cornerstone for the large scale implementation of advanced water treatments based on adsorption processes. In other words, producing low-cost, disposable carbonaceous adsorbents which could be applied for pollution control on a "use-and-throw" basis [4-9].

In this regard, the utilization of residues as precursors in the obtaining of low-cost highvalue carbon adsorbents is an interesting strategy that enables to deal with the problem of waste disposal, and, at the same time, assess the potential possibilities for waste recycling by its application in the removal of toxic pollutants from water.

The thermo-chemical conversion of agricultural waste and by-products has received increasing attention in the last decades due to its potential application in different fields such as energy production and the obtention of chemical products and adsorbents. In this connection, a number of works report the preparation of carbon-based adsorbents from cheaper and readily available precursor materials (agricultural by-products and other biomass materials) by chemical and physical activations [10-16]. The pyrolysis of agricultural wastes is an important step in its thermal conversion, since it determines the 
split between the different phases: char, tar and gas. The regular morphology of the lignocellulosic waste results in an excellent precursor for the preparation of activated carbons. The objective of this work is to investigate the preparation of activated carbons with high adsorption activity towards As (III) and Mn (II) ions from aqueous solutions, using an agricultural residue as carbon precursor (i.e., bean pods). The biomass waste was submitted to pyrolysis in the presence of water vapor, and the obtained porous material was used for the removal of toxic heavy metals.

\section{Experimental}

\subsection{Materials}

Initially, the chemical composition (organic matter fractions) of the carbon precursor was analyzed. Details on the experimental procedure has been described elsewhere [17]. Briefly, a two wet-chemical method was used, yielding four fractions: soluble in a toluene-ethanol mixture, soluble in 0.94 mol. $\mathrm{L}^{-1}$ sulfuric acid, soluble in $13.5 \mathrm{~mol} . \mathrm{L}^{-1}$ sulfuric acid and insoluble in $13.5 \mathrm{~mol} . \mathrm{L}^{-1}$ sulfuric acid. Lipids were solubilized by the first extraction step, proteins and hemicellulose by the second step, and cellulose by the third step. The lignin remained in the residual fraction.

\subsection{Preparation of the activated carbons}

Bean pods were used as carbonaceous precursor for the preparation of activated carbons. Around $50 \mathrm{~g}$ of the raw material (fraction of $1-5 \mathrm{~mm}$ ) was heated in a laboratory installation at atmospheric pressure and heating rate of $60^{\circ} \mathrm{C} \mathrm{min}^{-1}$ up to a carbonization temperature of $600{ }^{\circ} \mathrm{C}$. The sample was maintained at the final temperature for $10 \mathrm{~min}$, 
and then cooled down to ambient temperature. Subsequently, the solid product was activated at $700{ }^{\circ} \mathrm{C}$ with water vapor for $1 \mathrm{~h}$ time of activation. The obtained activated carbon will be referred to in the text as carbon A.

\subsection{Characterization of porous texture}

Textural characterization was carried out by measuring the $\mathrm{N}_{2}$ adsorption isotherms at $196^{\circ} \mathrm{C}$ in an automatic apparatus (Micrometrics ASAP $2010 \mathrm{M}$ ). Prior to the adsorption measurements the samples were outgassed in-situ under vacuum at $300^{\circ} \mathrm{C}$ overnight, to remove any adsorbed moisture and/or gases. The isotherms were used to calculate specific surface area $\mathrm{S}_{\mathrm{BET}}$, and total pore volume $\mathrm{V}_{\mathrm{T}}$. The pore size distribution, micropore and mesopores volumes have been obtained applying the DFT model to the $\mathrm{N}_{2}$ adsorption data, assuming a slit-shape pore geometry [18].

\subsection{Oxygen functional group}

The content of oxygen-containing functional groups with acidic character on the carbon surface was determined applying the Boehm method by neutralization with bases of increasing strength: $\mathrm{NaHCO}_{3}, \mathrm{Na}_{2} \mathrm{CO}_{3}, \mathrm{NaOH}$ and sodium ethoxide [19]. About $0.5 \mathrm{~g}$ ( \pm $0.0001 \mathrm{~g}$ ) of the carbon was put in contact with $100 \mathrm{~mL}$ of $0.05 \mathrm{~N}$ base solution in sealed flasks. The suspensions were shaken at least 16 hours, and then filtered. The excess of base remaining in the solution was determined from back-titration after adding an excess of standard $\mathrm{HCl}$ solution. It was assumed that sodium $\mathrm{NaHCO}_{3}$ was capable of neutralizing all carboxylic groups, $\mathrm{Na}_{2} \mathrm{CO}_{3}$ - carboxylic and lactonic groups, $\mathrm{NaOH}$ carboxylic, lactonic and phenolic groups, and sodium ethoxide was assumed to neutralize 
all acidic groups. The total number of basic sites was determined with $0.05 \mathrm{~N} \mathrm{HCl}$ [20]. The procedure is the same as above mentioned, as back-titration of the excess of $\mathrm{HCl}$ was performed using titration with $0.05 \mathrm{~N} \mathrm{NaOH}$ solution.

\section{5. $p H$ measurements}

The $\mathrm{pH}$ of the carbons was measured according to the following procedure: Exactly $4.0 \mathrm{~g}$ of carbon was weighed into a $250-\mathrm{mL}$ beaker, and $100 \mathrm{~mL}$ of water was added. The beaker was covered with a watch glass, and the mixture was boiled for 5 min. The suspension was set aside, and the supernatant liquid was poured off as hot as possible but not below $60^{\circ} \mathrm{C}$. The decanted portion was cooled to ambient temperature and its $\mathrm{pH}$ was measured to the nearest $0.1 \mathrm{pH}$ unit.

\subsection{Point of zero charge ( $\left.\mathrm{pH}_{\mathrm{PZC}}\right)$}

The nature of the carbon surface was determined from the $\mathrm{pH}$ value corresponding to the point of zero charge $\left(\mathrm{pH}_{\mathrm{PZC}}\right)$. This was measured by the mass titration method as described by Noh and Schwarz [21], employing the following procedure. Briefly, the activated carbon was dispersed in a suitable volume of distilled water and stored with constant stirring under a nitrogen atmosphere at room temperature until equilibrium was attained (ca. 48 h). Typical activated carbon/water ratios employed were 1, 2, 4, 6, 8, 10, 12,14 and 16 . Once equilibrium had been reached, the $\mathrm{pH}$ value was measured via a glass electrode. Newly portion of distilled water was then added in order to obtain the next solid/weight fraction. The plateau in the plot of equilibrium $\mathrm{pH}$ versus solid weight fraction corresponded to the $\mathrm{pH}_{\mathrm{PZC}}$ value of the activated carbon. 


\subsection{Adsorption measurements}

\subsubsection{Adsorption of As (III)}

All adsorption experiments (equilibrium and kinetics) were carried out using a $0.2 \mathrm{~mm}$ particle size fraction. An arsenic (III) standard solution $\left(1000 \mathrm{mg} \mathrm{L}^{-1}\right)$ was prepared by dissolving $1.3200 \mathrm{~g}$ of $\mathrm{As}_{2} \mathrm{O}_{3}$ in $25 \mathrm{~mL}$ of $1.0 \mathrm{M} \mathrm{NaOH}$. The solution was diluted to about $100 \mathrm{~mL}$ with water, adding 2 drops of $0.2 \%$ phenolphthalein. It was then neutralized with $1.0 \mathrm{M} \mathrm{HCl}$ and further diluted to $1 \mathrm{~L}$ [22]. This stock solution was diluted to obtain standard solutions containing 5-20 $\mathrm{mg} \mathrm{L}^{-1}$ of As (III).

Initially, the kinetics of adsorption were carried out to investigate the effect of the initial concentration $\left(5,10,1520 \mathrm{mg} \mathrm{L}^{-1}\right)$ on the rate and amount adsorbed, and to evaluate the time needed for reaching equilibrium conditions. Batch adsorption studies were carried out using $25 \mathrm{~mL}$ of arsenic (III) solution of the desired initial concentration were mixed with ca. $250 \mathrm{mg}$ of the activated carbon in a $100 \mathrm{~mL}$ conical flask. The adsorbentadsorbate suspension was stirred at room temperature by mechanical shaker, and several samples were collected between 5 min and $6 \mathrm{~h}$. After filtration, using microporous paper filters, the amount of arsenic (III) remaining in the solution was determined by titration with iodine [23], using starch as indicator. The reaction between iodine and $\mathrm{As}_{2} \mathrm{O}_{3}$ is showed as follows:

$$
\left.\mathrm{As}_{2} \mathrm{O}_{3}+2 \mathrm{~J}_{2}+2 \mathrm{H}_{2} \mathrm{O} \rightarrow \mathrm{As}_{2} \mathrm{O}_{5}+4 \mathrm{HI} \quad \text { (r. } 1\right)
$$

Equilibrium adsorption isotherms were obtained at room temperature, varying the initial concentration $\left(5-20 \mathrm{mg} \mathrm{L}^{-1}\right)$ and recalculating the amount adsorbed after the equilibrium 
conditions were reached. The stirring time of $2 \mathrm{~h}$ was selected for the equilibrium essays since, according with the results of the kinetic essays; between 1 and $6 \mathrm{~h}$ the uptake was practically the same and did not change even after $24 \mathrm{~h}$ of stirring. Arsenic uptake was calculated according to Eq. (1)

$q_{t}=\frac{\left(C_{0}-C_{t}\right)}{W} V$

where $q_{t}$ is the amount $\left(\mathrm{mg} \mathrm{g}^{-1}\right)$ adsorbed at time $t, C_{0}$ is the initial As(III) concentration in solution ( $\left.\mathrm{mg} \mathrm{L}^{-1}\right), C_{t}$ is the final As(III) concentration in solution at time $t\left(\mathrm{mg} \mathrm{L}^{-1}\right), V$ is the volume $(\mathrm{L})$ of the adsorbate solution and $W(\mathrm{~g})$ is the mass of activated carbon.

The effect of solution $\mathrm{pH}$ on the equilibrium adsorption of As (III) on the carbon adsorbents was investigated using $250 \mathrm{mg}$ adsorbent and $20 \mathrm{mg} \mathrm{L}^{-1}$ As (III) concentration at $1 \mathrm{~h}$ time of treatment. Hydrochloric acid and sodium hydroxide were used for adjusting the $\mathrm{pH}$ of the system.

\subsubsection{Determination of As (V)}

Although the standard solutions are prepared from $\mathrm{As}_{2} \mathrm{O}_{3}$, the conversion of $\mathrm{As}$ (III) to $\operatorname{As}(V)$ species may be catalyzed by carbon, for which the concentration of $\mathrm{As}(\mathrm{V})$ species in the solutions was also monitored. The determination of the $\operatorname{As}(\mathrm{V})$ species was carried out as follows. An arsenic (V) standard solution $\left(1000 \mathrm{mg} \mathrm{L}^{-1}\right)$ was prepared by mixing $25 \mathrm{~mL}$ of $1000 \mathrm{mg} \mathrm{L}^{-1}$ As (III) standard solution with $25 \mathrm{~mL}$ of freshly prepared aqua regia $\left(3: 1 \mathrm{HCl} / \mathrm{HNO}_{3}\right.$ mixture) in a $150 \mathrm{~mL}$ beaker [22]. After evaporation to dryness in a hot water bath, the As (V) product was diluted with distilled water up to $25 \mathrm{~mL}$. Intermediate standard solutions were prepared from this solution by a series of dilutions using distilled water. The initial and equilibrium concentrations of As (V) ions in the 
solution were determined at $845 \mathrm{~nm}$ on a Specord UV-vis spectrophotometer, using the following procedure: an aliquot of test solution was placed in a $25 \mathrm{~mL}$ volumetric flask, then $2.5 \mathrm{~mL}$ of hydrazine sulfate and $10 \mathrm{~mL}$ of $1 \mathrm{M} \mathrm{HCl}$ were added. A calibration curve for $5-50 \mu \mathrm{g}$ of As $(\mathrm{V})$ in a $25 \mathrm{~mL}$ flask by the previous procedure was made. A suitable aliquot $(10 \mathrm{~mL})$ of solution containing As $(\mathrm{V})$ was transferred to a $25 \mathrm{~mL}$ volumetric flask.

\subsubsection{Adsorption of $\mathrm{Mn}$}

A stock manganese aqueous solution was prepared by dissolving of $0.2748 \mathrm{~g} \mathrm{MnSO}_{4}$ in $10 \mathrm{~mL}$ hot $\mathrm{H}_{2} \mathrm{SO}_{4}$ and the solution was diluted to $1 \mathrm{~L}$ with distilled water. Standard solutions of different concentrations were obtained by dilutions. As in the case of arsenic, the adsorption capacity of manganese was determined varying the initial concentration. Briefly, $100 \mathrm{~mL}$ of manganese (II) solution of the desired initial concentration were mixed with ca. $250 \mathrm{mg}$ of the activated carbon in a conical flask and stirred until equilibrium was reached. The amount of ions in the solution was calculated from the oxidation reaction of $\mathrm{Mn}$ (II) to $\mathrm{MnO}_{4}^{-}$, using $\mathrm{K}_{2} \mathrm{~S}_{2} \mathrm{O}_{8}$ in $\mathrm{HNO}_{3}$ acidic solution as oxidizing agent and $\mathrm{Ag}^{+}$as catalyst [24]. The concentration of permanganate anions was estimated using Specord UV-VIS spectrophotometer.

The equilibrium adsorption isotherms were fitted to the Langmuir model [25], to evaluate the maximum loading capacity of the activated carbon, using the linear form proposed by Cheremishinoff [26]:

$$
\mathrm{C}_{\mathrm{e}} / \mathrm{q}_{\mathrm{e}}=1 / \mathrm{Q}_{0} \mathrm{~b}+\mathrm{C}_{\mathrm{e}} / \mathrm{Q}_{0}
$$


where $\mathrm{C}_{\mathrm{e}}\left(\mathrm{mg} \mathrm{L}^{-1}\right)$ is the equilibrium concentration and $\mathrm{q}_{\mathrm{e}}(\mathrm{mg} / \mathrm{g})$ is the amount of metal adsorbed at equilibrium, $Q_{o}$ and $b$ are Langmuir constants, related to adsorption capacity and energy of adsorption, respectively.

\section{RESULTS AND DISCUSSION}

\subsection{Chemical composition}

The bean pods used as carbon precursors contained a relatively high volatile matter (ca. 80 wt. \%), what suggests that this residue will not present a high carbon yield after pyrolysis (12 wt. \%), however, it is a cheap, easy to handle and largely available waste. Bean pod waste is different from other wood or other lignocellulosic materials. The typical composition is $33 \%$ cellulose, $45.6 \%$ hemi-cellulose, $17 \%$ lignin and a small amount of lipids (4.47 wt \%). Moreover, the elemental analysis shows a low ash content and a relatively high oxygen content (almost 50 wt. \%).

The chemical composition of the corresponding activated sample -carbon A-, obtained after pyrolysis and water vapor activation of the bean pod waste is also compiled in Table 1. The activated counterpart presents a large oxygen content, indicating that some oxygen is incorporated to the carbonaceous matrix during pyrolysis and/or activation, either at the edges of the basal planes, or to the basal planes of the carbon, giving rise to different surface functionalities. This issue will be further addressed in the manuscript.

\subsection{Textural properties of the porous structure of the activated material}

Detailed characteristics of the porosity of the prepared carbon are summarized in Table 2. The nitrogen isotherm and the corresponding pore size distribution obtained by applying 
DFT model are shown in Figure 1. It is observed that the isotherm of produced carbon presents a type I-IV hybrid shape, according to the BDDT classification [27], with a hysteresis loop (H4 types) in the desorption branch at relative pressures above 0.5 , which is associated with capillary condensation in slit-shaped mesopores [28]. Although the apparent surface area of the carbon is rather low, as so the pore volumes are, indicating a poor development of the porosity, the carbon present interesting porous features. The carbon displays a narrow PSD within the micropore range (inset in Figure 1), with a maximum located between 1-2 $\mathrm{nm}$, therefore indicating that the microporosity of this carbon is composed of pores of large dimensions. The ratio between the calculated micropore and mesopore volumes (ca. 4.9) also confirms that the obtained carbon is highly microporous. This finding is in good agreement with earlier results on the development of carbon materials from biomass precursors [12]. We have reported that the composition of agricultural by-products has a strong influence on the final porous and chemical features of solid product obtained from pyrolysis and activation [12]. It was found that low ratios of lignine:cellulose favour the development of predominantly microporous materials.

In sum, it can be inferred that bean pods are excellent candidates for preparation of microporous carbons, due to an adequate combination of cellulose and lignin. The carbon, although posses low surface area, shows an interesting distribution of micropores of large sizes.

\subsection{Oxygen Functional Groups}


The identification and quantification of the surface oxygen groups in the prepared carbon was done by means of the point of zero charge and Boehm titration. The results are shown in Table 2. Despite the large amount of oxygen of the activated carbon, the activated carbon is basic adsorbent according to the value of $\mathrm{pH}_{\mathrm{PZC}}$. This suggests that the majority of the surface groups are predominantly of basic nature. This finding was confirmed by the identification of the oxygen-containing groups by Boehm titration. Acidic groups (carboxylic or lactone-like binding structures) were not detected. In contrast, the carbon presents a high amount of basic groups -evaluated by reaction in $\mathrm{HCl}-$, and a fair amount of phenol-type and carbonyl groups (Table 2). Comparing with most commercial carbons of basic nature, carbon A displays higher oxygen content. It seems that the oxygen-containing functionalities would be incorporated to the basal planes of the carbon, likely as ether, furanic and/or chromene-like structures which are known to have a strong basic character [29]. On the other hand, the carbon also possesses a high ash content, therefore the basic nature might also be associated to the mineral matter of the carbon (Lewis basic structures). This unusual characteristic has also been reported on activated carbons obtained from other lignocellulosic precursors such as cork powder [30,31].

\subsection{Adsorption of metal ions}

The potential application of the activated carbon obtained form the biomass waste for the removal of heavy metals from aqueous solutions was explored.

In general, it is considered that adsorption of arsenic and manganese ions from aqueous phase on carbonaceous adsorbents occurs in two steps; firstly, the transfer of sorbate from 
the aqueous phase to the accessible active sites on the carbon surface, followed by a second step consisting of the chemical complexation and/or ion exchange at the chemically active sites [32-34]. Given the nature of the prepared adsorbent (i.e., basic nature and high ash content), this materials seems a promising candidate for the removal of the toxic ions.

\subsubsection{Arsenic (III) removal from aqueous solution on bean pods activated carbon}

Initially, we investigated the adsorption of As (III) ions from solutions containing different initial concentration $\left(5,10,15\right.$ and $\left.20 \mathrm{mg} \mathrm{L}^{-1}\right)$. Although the standard solutions were prepared from $\mathrm{As}_{2} \mathrm{O}_{3}$, we observed a high catalytic activity of the carbon for the conversion of $\mathrm{As}(\mathrm{III})$ to $\mathrm{As}(\mathrm{V})$ species.

In order to estimate this catalytic activity of bean pods carbon in the reaction of oxidation of As (III) to As (V), the accumulation rate of As (V) in the aqueous solution was investigated. As an example, the effect of contact time for a solution of $10 \mathrm{mg} \mathrm{L}^{-1}$ initial concentration and at $\mathrm{pH} 7$ is shown in Figure 2.

It can be seen a rapid increase of the content of As (V) at short contact time (i.e., the initial steps of the adsorption); after 50 minutes the amount of $\operatorname{As}(\mathrm{V})$ is constant, indicating that equilibrium has been reached. The amount of arsenate ions as a the result of the catalytic effect of the activated carbon also depends on the initial concentration of the As(III) solution; the conversion ranges between $10-30 \%$ in the studied range of concentrations of $5-20 \mathrm{mg} \mathrm{L}^{-1}$. Similar results of the oxidation of As (III) to As (V) promoted by activated carbons from agricultural wastes have been previously reported [32]. 
Figure 3 shows the effect of the kinetics of As(III) removal at various initial concentrations. Arsenic ions uptake increases sharply at short contact times and slows gradually at contact time above $30 \mathrm{~min}$. For large contact time, the shape of the kinetic plot becomes smother, indicating that equilibrium conditions are approaching. Indeed, data indicates that the equilibrium is attained after $60 \mathrm{~min}$ for all the initial concentrations of As (III) solutions. The changes in the amount adsorbed at large contact time become very small, suggesting the possibility of formation of monolayer coverage of As (III) on the surface of the adsorbent. This behavior can be attributed to the relative decrease in the number of available sites on the carbon surface as the adsorption process proceeds.

The adsorption isotherm of As (III) on the synthesized carbon is presented in Figure 4. The fitting of the experimental data to the Langmuir model shows a good agreement, with a calculated correlation coefficient $\mathrm{R}=0.974$. This confirms that the removal of As (III) from solution on the prepared carbons can be described by the Langmuir theory, which states that adsorption proceeds via a monolayer formation. Indeed, the linear plot of the isotherm (not shown) displayed the typical L-shape according to Giles classification [35], confirming that adsorption proceeds via saturation at low adsorbent doses. The maximum adsorption capacity evaluated for the A carbon was $1.01 \mathrm{mg} / \mathrm{g}$, and energy of adsorption $-3.40 \mathrm{~L} / \mathrm{mg}$.

Comparatively with the results reported in the literature (see Table 3) bean pod-derived activated carbons presents one of the highest loading capacity, only outperformed by an activated carbon obtained from activation of olive stones [32]. In this regard, it should be mentioned that carbon A has a specific BET surface $\left(258 \mathrm{~m}^{2} \mathrm{~g}^{-1}\right)$ about 4 times lower than the carbon obtained from olive stones $\left(1030 \mathrm{~m}^{2} \mathrm{~g}^{-1}\right)$. Therefore if the adsorption 
capacity is normalized vs. this parameter, the performance of the biomass-derived carbon is greater. This finding must be related to the chemical composition of the adsorbents. Given its poor porous development, the most remarkable characteristic of carbon A are its highly basic nature with large oxygen and ash content. It seems that basic carbon surfaces favor the uptake of $\mathrm{As}(\mathrm{III})$ ions from aqueous solution. A synergistic and or catalytic effect due to the mineral matter should also be considered.

\subsubsection{Adsorption of $M n$}

The equilibrium adsorption isotherm of Mn (II) on activated carbon from bean pods is presented in Fig. 5. The adsorption isotherm belongs to the L(2)-type according to the Giles classification [35], showing a steep initial rise and a concave curvature at low equilibrium concentrations followed by a plateau or saturation limit. The linear plot of equation isotherm shows that the adsorption obeys the Langmuir model (Figure 5). This evidences a monomolecular adsorption of Mn (II) ions. The correlation coefficient is 0.998 , and the calculated $\mathrm{Q}_{0}$ and $\mathrm{b}$ values are $23.4 \mathrm{mg} \mathrm{g}^{-1}$ and $14.35 \mathrm{~L} \mathrm{mg}^{-1}$, respectively. Comparing the loading capacity with that reported in the literature for other materials, the biomass-derived carbon -A sample- outperforms other adsorbents. As a few examples, maximum manganese adsorption capacity of maize cob [36] is $2.28 \mathrm{mg} \mathrm{g}^{-1}, 2.21 \mathrm{mg} \mathrm{g}^{-1}$ for palm fruit bunch [36], $1.28 \mathrm{mg} \mathrm{g}^{-1}$ for iron-rich industrial co-products [40], $4 \mathrm{mg} \mathrm{g}^{-1}$ for natural zeolites [41] and $0.385 \mathrm{mg} \mathrm{g}^{-1}$ for manganese coated sand [42]. It is remarkable that carbon $\mathrm{A}$ is capable of retain over 10 times the uptake of the above mentioned materials, despite its poor textural development.

Previous investigations carried out in our research group on the influence of porous structure and chemical nature (i.e., acidic or basic) of the adsorbents on the adsorption of 
manganese and arsenic on activated carbons, have suggested that both factors are key parameters in the overall adsorption activity $[32,33]$, although the role of each parameter had not been well clarified. The results obtained in this work confirm our former premise about the outstanding effect of basic character of the carbon surfaces on the overall adsorption activity towards Mn (II) and As (III). As it has been mentioned above, carbon A presents the largest adsorption capacity, despite its low porosity. This indicates that such adsorption behavior has to be connected to its high basicity, given by a large proportion of oxygen-containing functional groups of basic nature and a high mineral matter content.

Comparing manganese (II) adsorption capacity of an activated carbon obtained from olive waste [33], the adsorption capacity is about 10 times lower than that attained in the carbon prepared from bean pods. Even though the same activation procedure (water vapor) has been employed, both carbons exhibit important differences in the porous texture, chemical composition and nature of the carbon surface. The BET surface area, micropore volume $\left(\mathrm{W}_{\mathrm{o}}\right)$ and $\mathrm{pH}$ of the olive waste carbon are $1032 \mathrm{~m}^{2} \mathrm{~g}^{-1}, 0.355 \mathrm{~cm}^{3} \mathrm{~g}^{-1}$ and 8.8, respectively. The results indicate that apart from the lower developed surface area (almost 3 times lower), the determining factors for the adsorption of arsenic and manganese ions on the bean pods activated carbons are the high value of $\mathrm{pH}(10.7)$ and higher content of basic groups $(7.4 \mathrm{meq} / \mathrm{g})$. Our results show that activated carbons with strongly expressed basic character and higher content of basic groups are excellent adsorbents for the removal of ions of Mn (II) and As (III) from water solutions.

\subsubsection{Influence of the $\mathrm{pH}$ of the solution.}


It is well known that solution $\mathrm{pH}$ is a critical factor in adsorption from solution; not only carbon surface properties change with variations of the $\mathrm{pH}$, but this parameter can also affect the state of the ionic species in solution.

The effect of $\mathrm{pH}$ on As (III) adsorption was studied in the initial $\mathrm{pH}$ range between 2 and 12, at a contact time of 60 min (Figure 6). The removal of As (III) increases with the $\mathrm{pH}$ of the system, and it reaches a maximum around 7-7 $\mathrm{pH}$ units. At $\mathrm{pH}$ above this value (strongly basic solutions), a sharp decrease is obtained in the uptake of As(III). The effect is particularly more remarkable at $\mathrm{pH} 12$, being the removal efficiency very low, close to $10 \%$.

This behavior is attributed to the changes in both the carbon surface. According to data shown in Table 2, the $\mathrm{pH}_{\mathrm{PZC}}$ of $\mathrm{A}$ carbon is 11.9. At low solution $\mathrm{pH}$ (acidic) the carbon surface is predominantly positively charged, whereas at strongly basic $\mathrm{pH}$ above the $\mathrm{pH}_{\mathrm{PZC}}$ negative charges appear on the surface, due to the dissociation of the functional groups. As a general rule, at solution $\mathrm{pH}$ below $\mathrm{pH}_{\mathrm{PZC}}$ the carbon surface is positively charged, and the number of the positive charges gradually decreases as the $\mathrm{pH}$ is raises. Moreover, the arsenic species on solution are also affected by the $\mathrm{pH}$. Below $\mathrm{pH} 7$, the neutral form $\left(\mathrm{H}_{3} \mathrm{AsO}_{3}\right)$ is predominant in the solution [43], and the carbon surface is positively charged. This corresponds to the maximum uptake, according to the data shown in Fig. 6. As pH increases, the amount of negative arsenic species $\left(\mathrm{H}_{2} \mathrm{AsO}_{3}{ }^{-}\right.$and $\mathrm{HAsO}_{3}{ }^{2-}$ ) rises while the positive charges decrease. At $\mathrm{pH}$ above $\mathrm{pH}_{\mathrm{PZC}}$, the negative charges on the surface appear and therefore the fall in the uptake is due to electrostatic repulsive interactions with the anionic forms of arsenic (III) - the dominant species at basic $\mathrm{pH}$ are $\mathrm{H}_{2} \mathrm{AsO}_{3}{ }^{-}[44]$ and $\mathrm{HAsO}_{3}{ }^{2-}[34]-$. 
Therefore, in acidic $\mathrm{pH}$ range most likely adsorption driving forces are Van der Waals forces between $\mathrm{H}_{3} \mathrm{AsO}_{3}$ and activated carbon, resulting in less adsorption. At near neutral $\mathrm{pH}$ values (7-9), along with physical adsorption, the low dissociation of weak arsenic acid $\left(\mathrm{H}_{3} \mathrm{AsO}_{3}\right)$ produces arsenite ion $\left(\mathrm{H}_{2} \mathrm{AsO}_{3}{ }^{-}\right)$, which is electrostatically attracted to the positive charges on the carbon surface (still solution $\mathrm{pH}$ is below $\mathrm{pH} \mathrm{PZC}_{\mathrm{PC}}$ ), this extracontribution enhances the overall uptake.

In sum, the role of the oxygen functional groups during the adsorption process is to contribute to the carbon basicity and/or to form complexes with As (III) ions.

Figure 7 shows the results of the effect of $\mathrm{pH}$ on removal of Mn (II) on bean pods carbon. The removal of manganese ionic species increases sharply between $\mathrm{pH} 2$ and 4. For $\mathrm{pH}>4$, the maximum uptake is attained and maintained constant as the solution $\mathrm{pH}$ becomes more basic. This might be attributed due to partial hydrolysis of Mn (II) ions with increasing $\mathrm{pH}$, resulting in the formation of complexes with $\mathrm{OH}-$ such as $\mathrm{MnOH}^{+}$ $\left.\mathrm{Mn}(\mathrm{OH})^{+}, \mathrm{Mn}(\mathrm{OH})_{2}, \mathrm{Mn}(\mathrm{OH})_{3}{ }^{-}, \mathrm{Mn}(\mathrm{OH})_{4}{ }^{2-}\right)$ and $\mathrm{Mn}(\mathrm{OH})_{2}$ species in solution [34]. As a result, Mn-hydroxyl species may participate in the adsorption and/or precipitation onto the adsorbent's structure. Similar behavior has been reported in zeolites [45]. The low solubility of some hydrolyzed Mn (II) species may be another reason for maximum adsorption in the $\mathrm{pH}$ range 5-6.

There are several plausible mechanisms for metal adsorption: ion-exchange, complexation (both specific adsorption pathways) or a combination of both. For the ion exchange process, and taking into account that the surface of the biomass-derived carbon 
is decorated with weak acidic (HA) and basic (B) sites, we can assume that ionization of these sites follows the reaction schemes below:

$$
\begin{aligned}
& \mathrm{HA}_{\text {(carbon) }} \leftrightarrow \mathrm{H}^{+}{ }_{(\mathrm{aq})}+\mathrm{A}_{\text {(carbon) }} \\
& \mathrm{B}_{\text {(carbon) }}+\mathrm{H}^{+}{ }_{(\mathrm{aq})} \leftrightarrow \mathrm{BH}^{+}{ }_{\text {(carbon) }}
\end{aligned}
$$

This being the case, the Mn (II) ions adsorption on the carbon surface may be described by the following reactions:

$$
\begin{array}{ll}
2 \mathrm{~A}^{-}+\mathrm{Mn}^{2+} \leftrightarrow\left(\mathrm{A}^{-}\right)_{2} \mathrm{Mn}^{2+} & \text { (r.4) } \\
\mathrm{A}^{-}+\mathrm{MnOH}^{+} \leftrightarrow\left(\mathrm{A}^{-}\right) \mathrm{MnOH}^{+} & \text {(r.5) } \\
\mathrm{Mn}(\mathrm{OH})_{2} \leftrightarrow \text { adsorption on non polar surface } & \text { (r.6) } \\
\mathrm{BH}^{+}+\mathrm{Mn}(\mathrm{OH})_{3}{ }^{-} \leftrightarrow\left(\mathrm{BH}^{+}\right) \mathrm{Mn}(\mathrm{OH})_{3}{ }^{-}
\end{array}
$$

On the basis of stability constants [46], it can be concluded that under our experimental conditions ( $\mathrm{pH} \sim 5.5)$, the dominant species are $\mathrm{Mn}^{+}$ions, and therefore the prevailing reaction is probably (r.4); however, reactions (r.5) and (r.6) might also take place. At higher concentration a complexation with oxygen containing functional groups can be observed. In any cases, the presence of basic oxygen functionalities on the carbon surface seem to be needed to enhance the amount adsorbed via ion-exchange and complexation with the manganese ionic species.

\section{Conclusions}

The present study shows that waste of bean pods can be effectively used as precursor material for the preparation of activated carbon. As the raw material for preparing the activated carbon is a discarded waste from bean industries, this production is expected to be effective and low-cost. Due to an adequate chemical composition, pyrolysis and subsequent activation of the biomass waste yielded a porous adsorbent that displays an interesting and promising distribution of large micropores. 
Despite possessing a relatively low surface area $\left(258 \mathrm{~m}^{2} \mathrm{~g}^{-1}\right)$, the biomass-derived carbon presented large As (III) and Mn (II) adsorption capacities (23.4 and $23.4 \mathrm{mg} \mathrm{g}^{-1}$ ), outperforming the uptake reported in the literature for other adsorbents, including highly porous activated carbons.

The results obtained in this work confirm previous investigations on the outstanding effect of basic character of the carbon surfaces on the overall adsorption activity towards Mn (II) and As (III). The results indicate that apart from the porosity, an outstanding factor in the adsorption of arsenic and manganese ions is the basic character of the carbon surfaces. Indeed, bean pods-derived carbonsposses a uniques combination of high basicity, given by a large proportion of oxygen-containing functional groups of basic nature and a high mineral matter content. The presence of basic oxygen functionalities on the carbon surface seem to be needed to enhance the amount adsorbed via ion-exchange and/or complexation with the ionic species in solution.

\section{Acknowledgements}

The authors thank the Bulgarian Academy of Sciences and the Division of International Affaires of CSIC for finantial support (projects CC1401 and 2007BG001, respectively). COA thanks the Spanish MEC for a Ramon y Cajal research contract. 


\section{References}

[1] WHO 2006. Guidelines for drinking-water quality. First addendum to third edition Vol. 1 Recommendations. World Health Organization (2006), ISBN 9241546964.

[2] Directive 2000/60/EC, EU Water Framework Directive. Off. J. L 327, on 22 December 2000.

[3] Roskill Report. The economics of activated carbon, Ed. Roskill Information Services Ltd., Claphham Road, London, 1998.

[4] M.A. Ferro-Garcia, J.A. Rivera-Utrila, J. Rodriguez-Gordillo, I. Bautista-Toledo, Carbon 26 (1988) 363.

[5] R. Dobrovolski, M. Jaroniec, M. Kosmuski, Carbon 24 (9861) 15.

[6] C. Namasivayam, K. Kadirvelu, Carbon, 37 (1999) 79.

[7] H. Altundogan, S. Altundogan, F. Tumen, M. Bildik, Waste Manag. 20 (2000) 761.

[8] C.O. Ania, J.B. Parra, A. Arenillas, F. Rubiera, T.J. Bandosz, J.J. Pis, Appl. Surf. Sci. 253 (2007) 5899.

[9] A. Arenillas, F. Rubiera, J.B. Parra, C.O. Ania, J.J. Pis, Appl. Surf. Sci. 252 (2005) 619.

[10] N. Petrov, Y. Budinova, M. Razvigorova, R. Zanzi, E. Bjornbom, V. Minkova, Proceedings of $2^{\text {nd }}$ Olle Lindstrom Symposium of Renewable EnergyBioenergy:Royal Institute of Technology; Stockholm, Sweden, 1999, p.16.

[11] N. Petrov, Y. Budinova, M. Razvigorova, R. Zanzi, E. Bjornbom, V. Minkova, Carbon 38 (2000) 2069.

[12] D. Savova, E. Apak, E. Ekinci, F. Yardim, N. Petrov, Y. Budinova, M. Razvigorova, V. Minkova, Biomass Bioenergy 21 (2001) 1333.

[13] C. Moreno-Castilla, F. Carrasco-Marin, M.V. Lopez-Ramon, M. Alvarez-Merino, Carbon 39 (2001) 1415.

[14] J. Hayashi, A. Kazehaya, K. Muroyama, A. Watkinson, Carbon 38 (2000) 1873.

[15] S. Dastgheib, D. Rockstraw, Carbon 39 (2001) 1849.

[16] B. Cabal, T. Budinova, C.O. Ania, B. Tsyntsarski, J.B. Parra, B. Petrova, J. Haz. Mater. 2008 (in press)

[17] F. Adani, P.L. Genevini, F. Tambone, Compost Sci. Utiliz. 3 (1995) 25.

[18] J.P. Olivier, J. Porous Mater. 2 (1995) 9.

[19] H.P. Boehm, in Eley, D.D., Pines,H., Wesz,P.B., (Eds.) Advances in catalysis; Academic Press:New York, 1966, Vol. 16, p179.

[20] Papier E.U., Li S., Donnet J, Carbon 25 (1987) 243.

[21] J.S. Noh J.S., J.A. Schwarz, J. Colloid Interf. Sci. 130 (1989) 157.

[22] L.K. Tan, J.E. Dutrizae, Anal.Chem., 57 (1985) 1027. 
[23] B. Zagorchev, in Analytical Chemistry, Techniki, Sofia, Bulgaria, 1967.

[24] Bulgarian standard 17.1.4.15-79.

[25] I.J. Langmuir, J. Amer. Chem. Soc., 40 (1918) 1368.

[26] P.N. Cheremishinoff, F. Eclerbusch, Carbon Adsorption Handbook; Ann Arbor Science Publishers: Ann Arbor, MI, 1978.

[27] L.S. Brunauer, W.E. Deming, E. Teller, , J. Amer. Chem. Soc. 62 (1940) 1723.

[28] F. Rouquerol, J. Rouquerol, K. Sing, Adsorption by powders \& porous solids, Academic Press, London, 1999.

[29] T.J. Bandosz, C.O. Ania, in Activated Carbon Surfaces in Environmental Remediation (Bandosz, Edt) in the series Interface Science and Technology, vol 7, Elsevier, New York, 2006, p159.

[30] P.J.M. Carrott, M.M.L. Ribeiro-Carrott, R.P. Lima, Carbon 37 (1999) 515.

[31] A.S. Mestre, J. Pires, J.M.F. Nogueira, A.P. Carvalho, Carbon 45 (2007) 1979.

[32] T. Budinova, N. Petrov, M. Razvigorova, J.B. Parra, P. Galiatsatou, Ind. Eng. Chem. Res., 45 (2006) 1896.

[33] D. Savova, T. Budinova, N. Petrov, Bulgarian Chem. Comm., 38 (2006) 283.

[34] R.M. Smith, A.E. Martell, in: Critical stability constants, inorganic complexes, vol. 4, New York and London:Plenum Pres; 1976, p.5.

[35] C.H. Giles, T.H. MacEwan, S.N. Nakhwa, D. Smith, J.Chem.Soc., (1960) 3973.

[36] M.M. Nassar, K.T. Ewida, E.E. Ebrahiem, Y.H. Magdy, Adsorption Sci. Technol., 22 (2004) 25.

[37] D.B. Singh, G. Prasad, D.C. Rupainwar, V.N. Singh, Water Air Soil Pollut., 42 (1998) 373.

[38] R. Vaishya, S.K. Gupta, J.Chem. Biotechnol. 78 (2002) 73.

[39] S. Maeda, A. Ohki, S. Saikoji, K. Naka, Sep. Sci. Technol., 27 (1992) 681.

[40] Y. Salingar, D.I. Sparks, J.D. Pesek, J. Environ. Qual., 23 (1994) 1205.

[41] E. Erdem, N. Karapinar, R. Donat, J. Colloid Interf. Sci. 28 (2004) 309.

[42] P.Y. Hu, Y.H. Hsich, J.C. Chen, C.Y. Chang, J Water Supply: Res. Technol.-AQUA, 53 (2004) 151.

[43] S.K. Gupta, K.Y. Chen, J.Wat.Pollution Control Fed. 50 (1978) 493.

[44] F.W. Pointius, J. Am. Water Works Assoc., 86 (1994) 6.

[45] K.S. Hui, C.Y.H. Chao, S.C. Kot, J. Haz. Mat., B127 (2005) 89.

[46] E.R. Nightingale, J Phys. Chem., 63 (1959) 1381. 


\section{Figure captions}

Figure 1. Nitrogen adsorption-desorption isotherms of the activated carbon obtained from bean pods and pore size distribution (inset) obtained by DFT method.

Figure 2. Effect of treatment time on the accumulation of $\mathrm{As}(\mathrm{V})(\%)$ in the result of the oxidation of As (III). Experimental conditions: As(III) concentration, $10 \mathrm{mg} \mathrm{L}^{-1}$ and $\mathrm{pH} 7.0$

Figure 3. Effect of treatment time and initical concentration on the removal of As(III) on the biomass-derived carbon. Experimental conditions: $250 \mathrm{mg}$ of carbon; $25 \mathrm{~mL}$ As(III) solution at $\mathrm{pH} 7$.

Figure 4. Experimental data (symbols) and Langmuir fitting (line) of the As(III) adsorption isotherms on the prepared carbon.

Figure 5. Manganese (II) adsorption equilibrium data on the bean pod-derived carbon. A) experimental adsorption isotherm in liner scale and B) Langmuir fitting of the data. .

Figure 6. Effect of $\mathrm{pH}$ on As(III) removal on bean pods carbon. Conditions: treatment time, $60 \mathrm{~min}$; carbon concentration, $250 \mathrm{mg} \mathrm{mL}^{-1}$; and $\mathrm{As}(\mathrm{III})$ concentration, $20 \mathrm{mg} \mathrm{L}^{-1}$.

Figure 7. Effect of $\mathrm{pH}$ on $\mathrm{Mn}(\mathrm{II})$ adsorption on the studied carbon. Conditions: treatment time, $30 \mathrm{~min}$; amount of carbon $0.1 \mathrm{~g}$; and Mn (II) initial concentration, 5 $\mathrm{mg} \mathrm{L}^{-1}$.

\section{Table captions}

Table 1. Proximate and ultimate analysis [wt. \%] of the raw precursor (bean pods) and the activated carbon obtained by water vapor activation -A carbon-

Table 2. Chemical and nanotextural parameters of the biomass-derived activated carbon obtained from Boehm method, point of zero charge and $\mathrm{N}_{2}$ adsorption isotherms at $-196^{\circ} \mathrm{C}$

Table 3. Comparison of the adsorption capacities for As(III) removal on the bean-pod carbon with those attaine in different adsorbents from literature 
Table 1.

\begin{tabular}{lcc|ccccc}
\hline & $\begin{array}{c}\text { Proximate analysis } \\
\text { [wt. \%] }\end{array}$ & \multicolumn{5}{c}{ Ultimate analysis [wt. \%] } \\
\hline & Ash $^{\text {df }}$ & Volatile $^{\text {daf }}$ & C & H & O & H/C & O/C \\
\hline Bean pods & 6.09 & 80.07 & 43.25 & 5.98 & 49.74 & 0.14 & 1.15 \\
\hline Carbon A & 22.8 & 30.26 & 60.25 & 3.90 & 34.96 & 0.06 & 0.58 \\
\hline
\end{tabular}

daf - moisture and ash-free material

df - moisture-free material

Table 2.

Gas adsorption data

\begin{tabular}{|c|c|c|c|c|}
\hline $\begin{array}{c}\mathrm{S}_{\mathrm{BET}} \\
{\left[\mathrm{m}^{2} \mathrm{~g}^{-1}\right]}\end{array}$ & $\begin{array}{l}V_{\text {TOTAL }}{ }^{a} \\
{\left[\mathbf{c m}^{3} \mathbf{g}^{-1}\right]}\end{array}$ & $\begin{array}{c}V_{\text {micro }}{ }^{b} \\
{\left[\mathrm{~cm}^{3} \mathrm{~g}^{-1}\right]}\end{array}$ & $\begin{array}{c}V_{\text {meso }}{ }^{b} \\
{\left[\mathrm{~cm}^{3} \mathbf{g}^{-1}\right]}\end{array}$ & $\begin{array}{c}\text { Ratio } \\
\text { Vmicro/Vmeso } \\
\end{array}$ \\
\hline 258 & 0.206 & 0.080 & 0.013 & 4.9 \\
\hline \multicolumn{5}{|c|}{ Chemical parameters } \\
\hline \multirow{2}{*}{ pH } & \multirow{2}{*}{ pH } & \multicolumn{2}{|c|}{ Acidic groups [meq $\left.\mathrm{g}^{-1}\right]^{\mathrm{c}}$} & Total basic \\
\hline & & Hydroxyl & Carbonyl & {$\left[\operatorname{meq} g^{-1}\right]^{d}$} \\
\hline 10.7 & 11.90 & 0.21 & 1.52 & 7.40 \\
\hline
\end{tabular}

${ }^{\text {a }}$ evaluated at relative pressure $=0.99$ in the $\mathrm{N}_{2}$ adsorption isotherms at $-196{ }^{\circ} \mathrm{C}$

${ }^{b}$ evaluated from the DFT method applied to the $\mathrm{N}_{2}$ adsorption isotherms at $-196{ }^{\circ} \mathrm{C}$

${ }^{c}$ evaluated from the Boehm method

d evaluated from the titration in $\mathrm{HCl}$

Table 3.

\begin{tabular}{cccc}
\hline Adsorbent & Reference & Characteristics & $\begin{array}{c}\text { Adsorption capacity } \\
{\left[\mu \mathbf{m o l ~ g}^{-1}\right]}\end{array}$ \\
\hline Activated carbon & This work & Precursor: bean-pod & 637 \\
Hematite & 37 & Inorganic & 2.65 \\
SMIOCS & 38 & sulfate-modified & 1.91 \\
red mud & 7 & iron oxide-coated sand & Red mud \\
Limestone & 39 & iron hydroxide loaded & 8.86 \\
Activated carbon & 32 & coral lime stone & 0.17 \\
& & Precursor: olive waste & 18.60
\end{tabular}




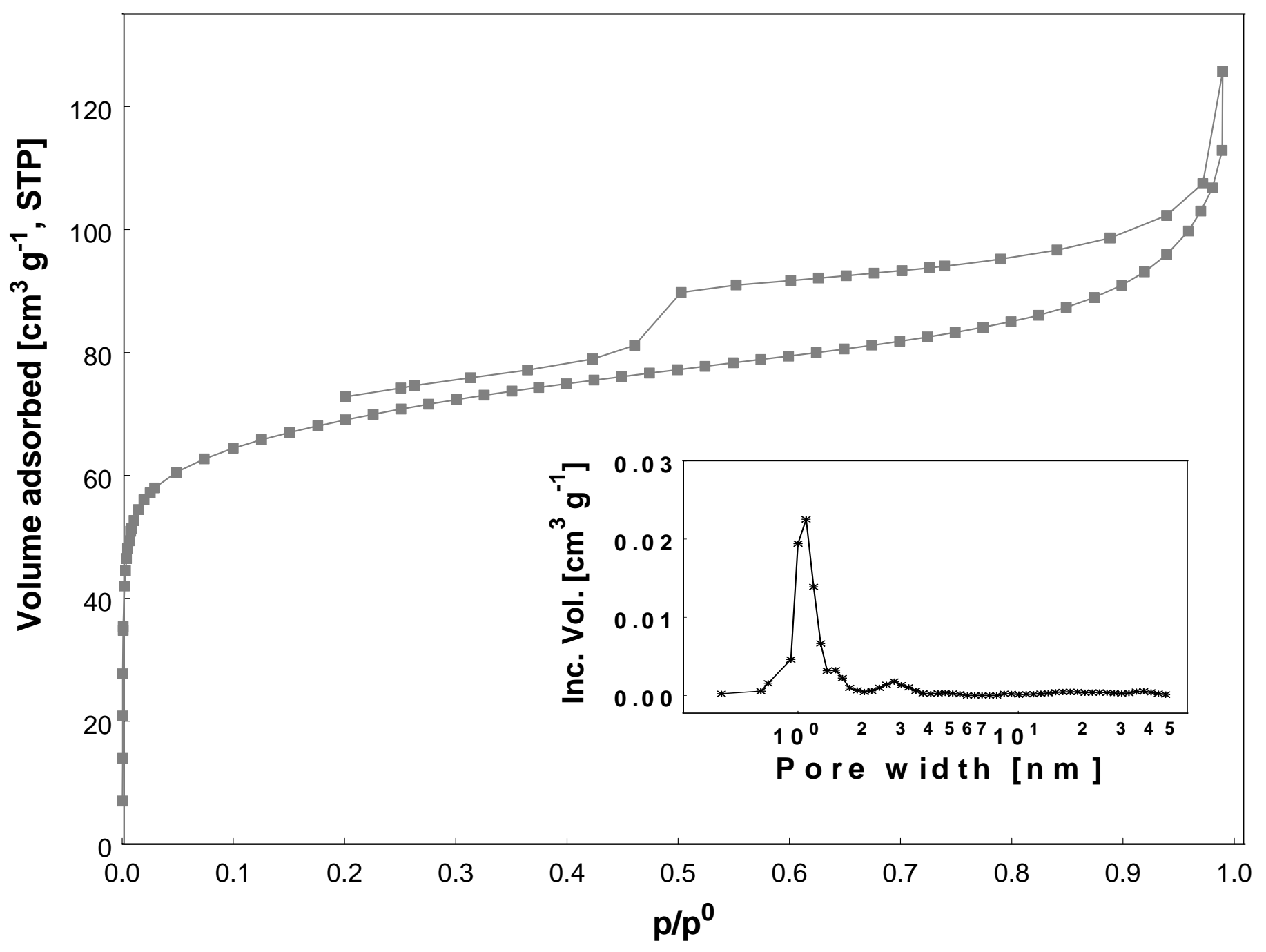

Figure 1. 


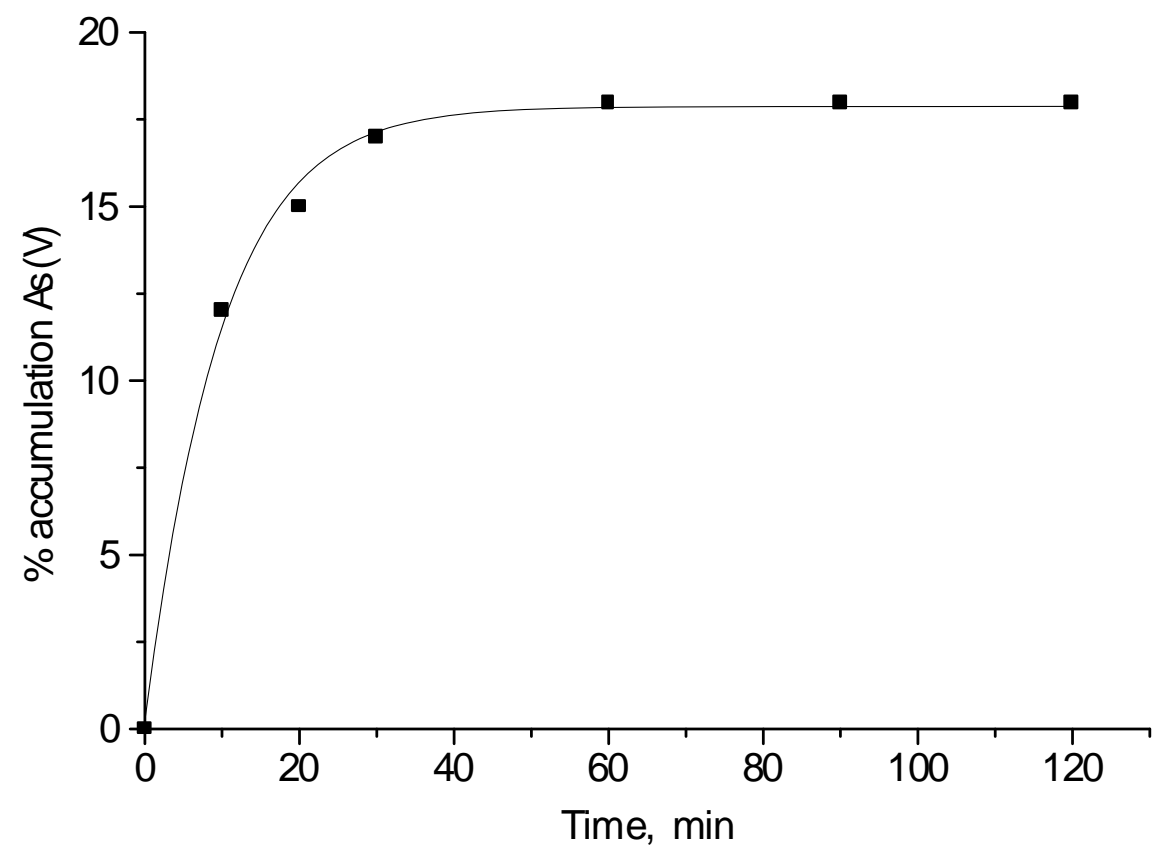

Figure 2. 


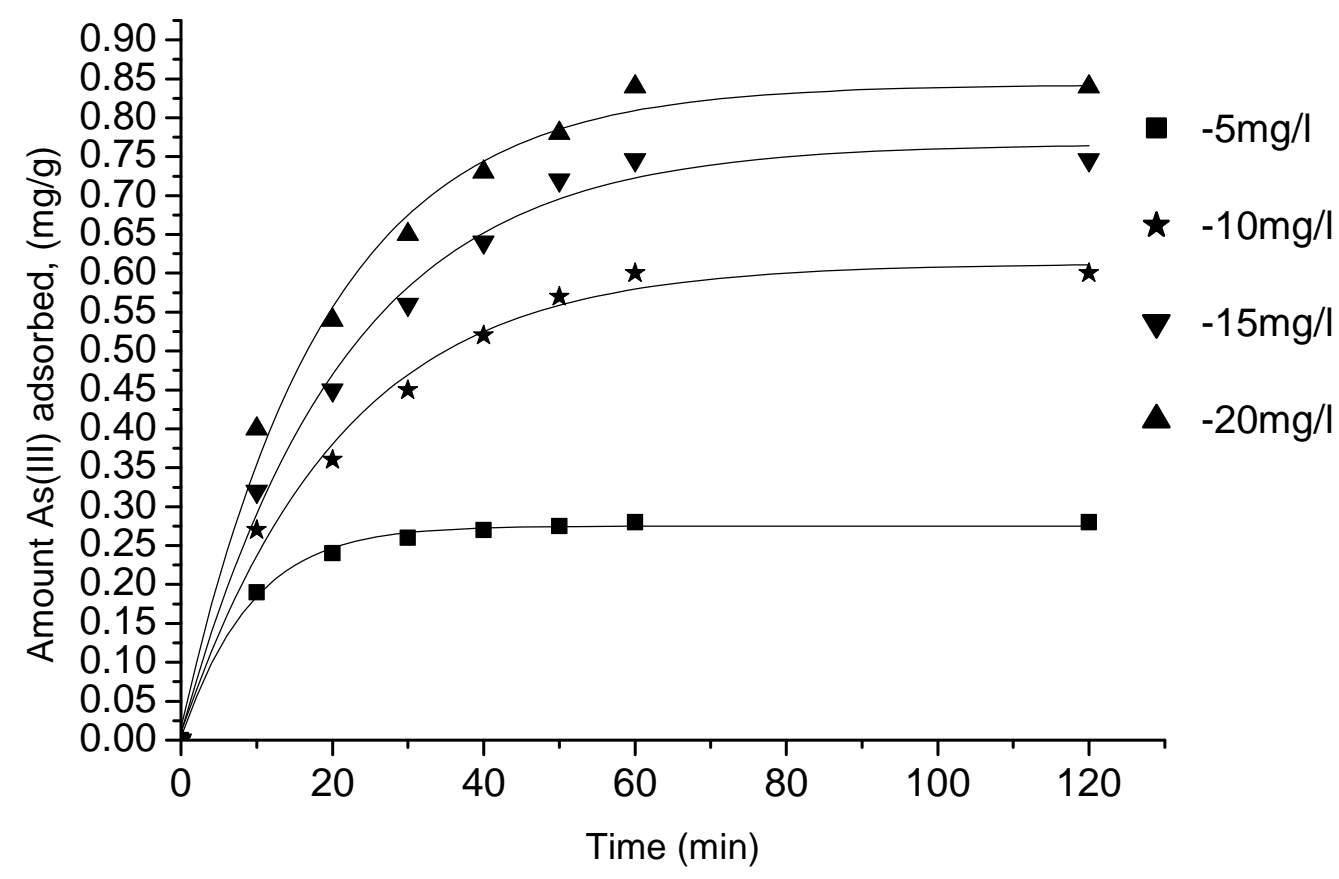

Figure 3. 


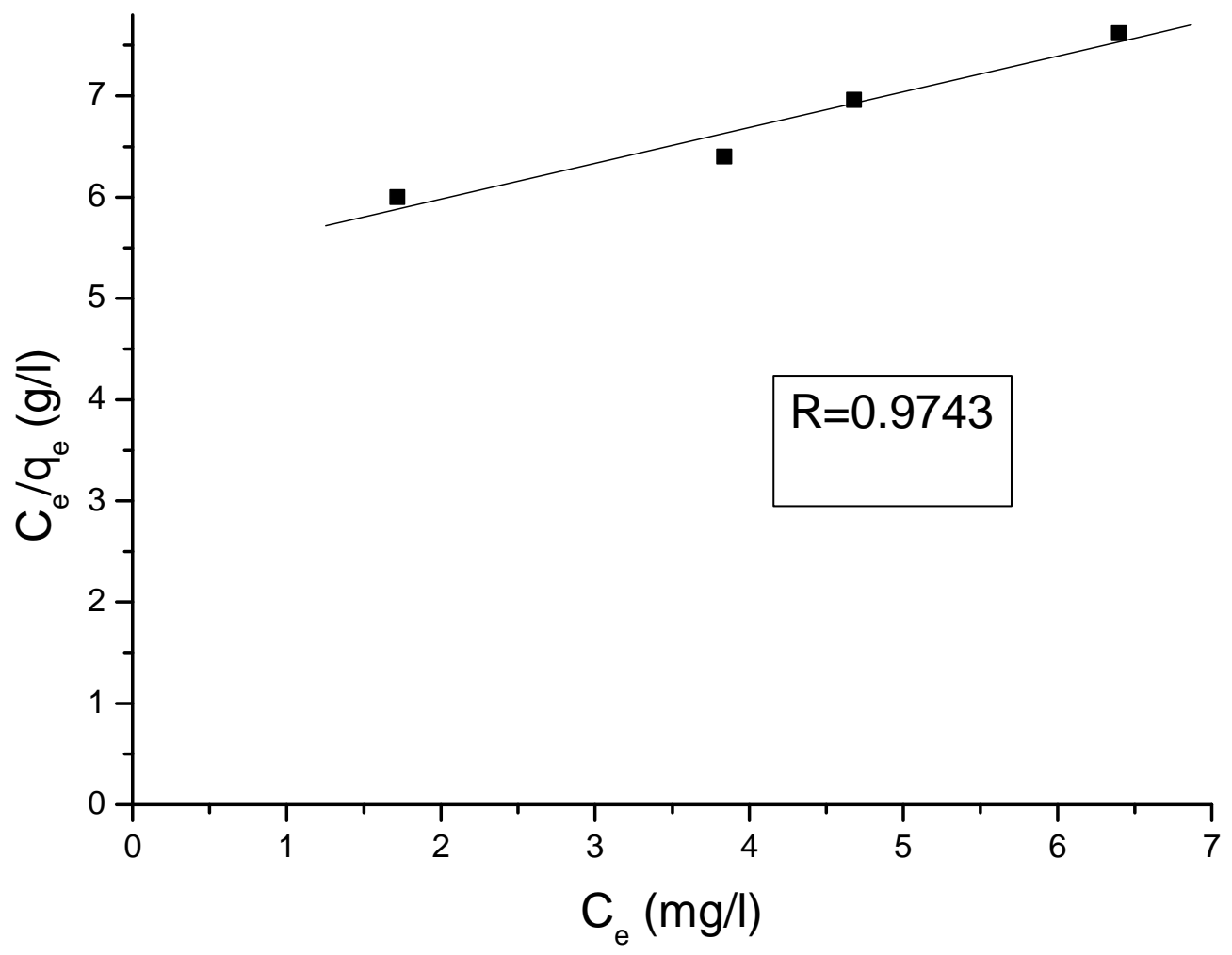

Figure 4. 


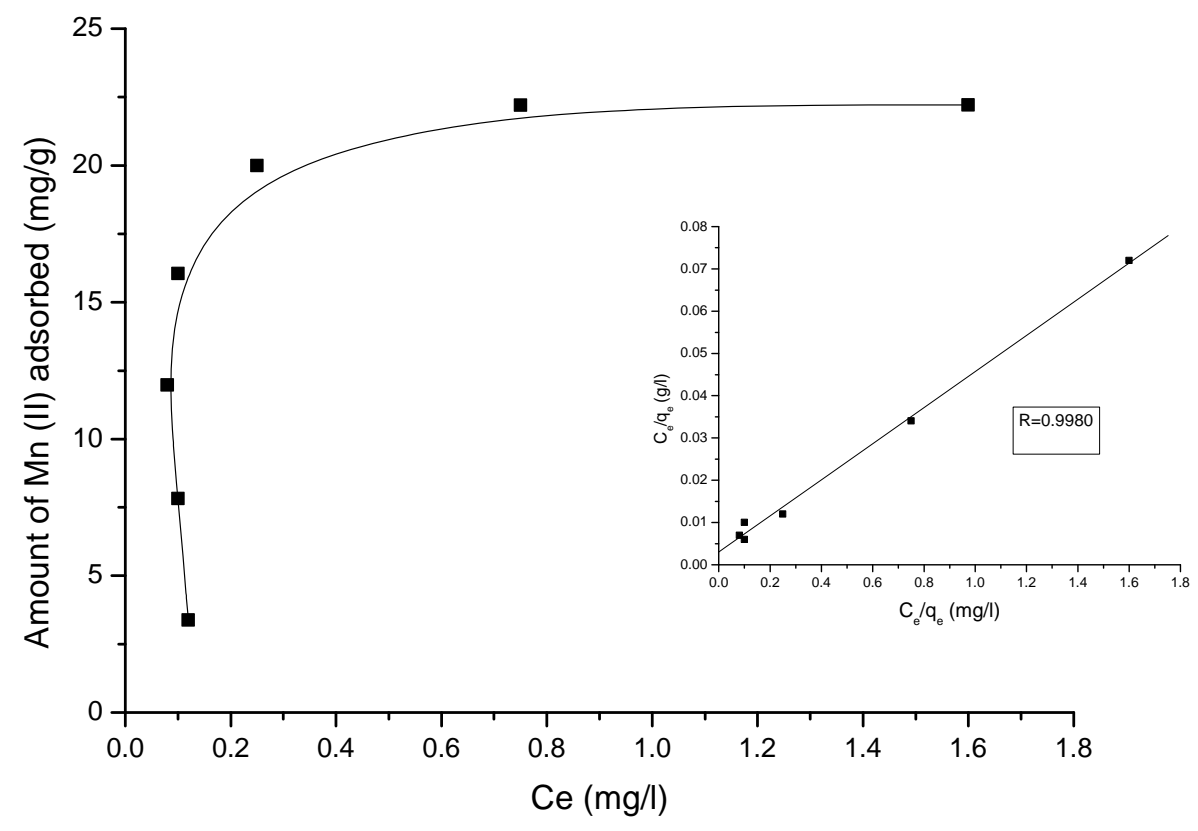

Figure 5. 


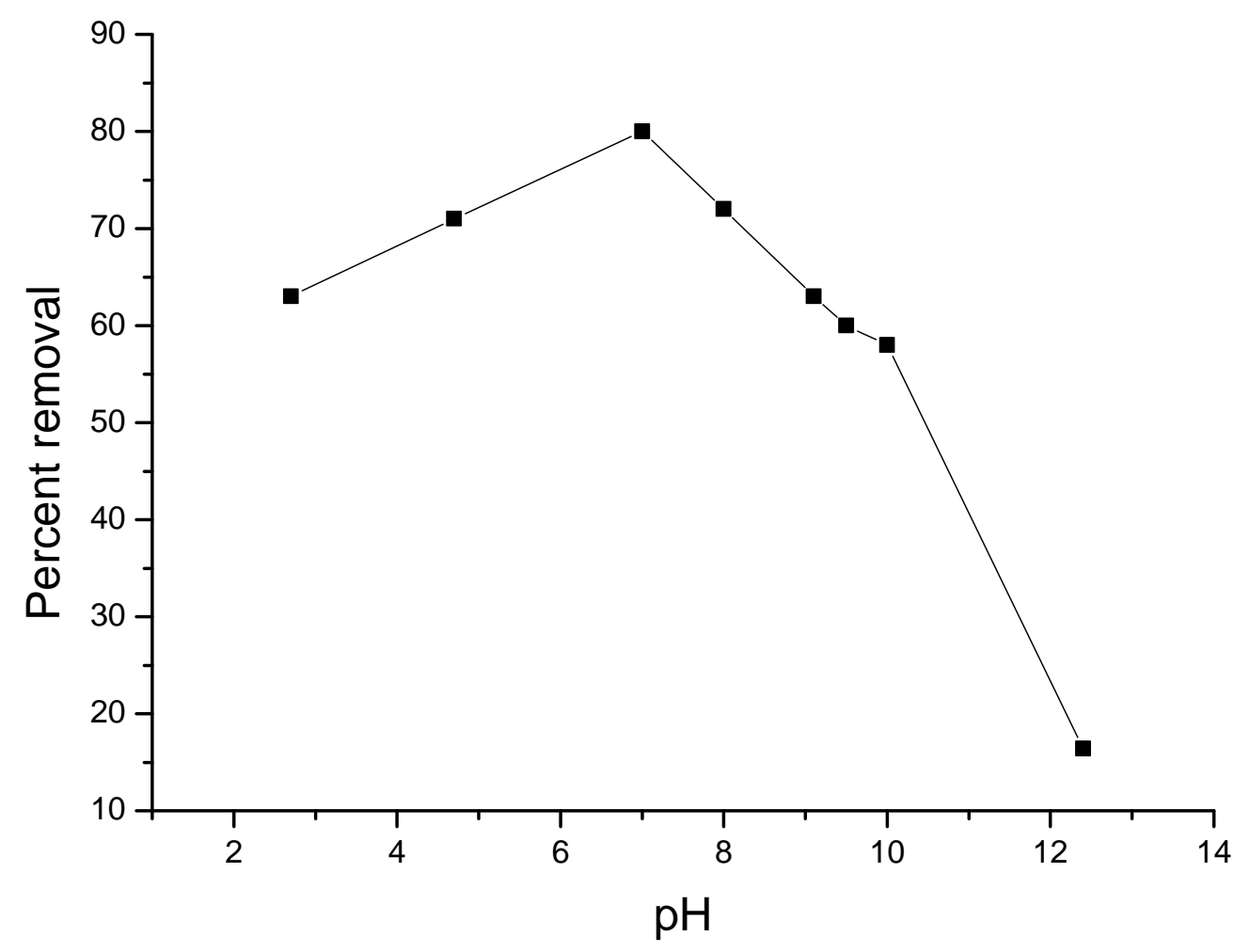

Figure 6 


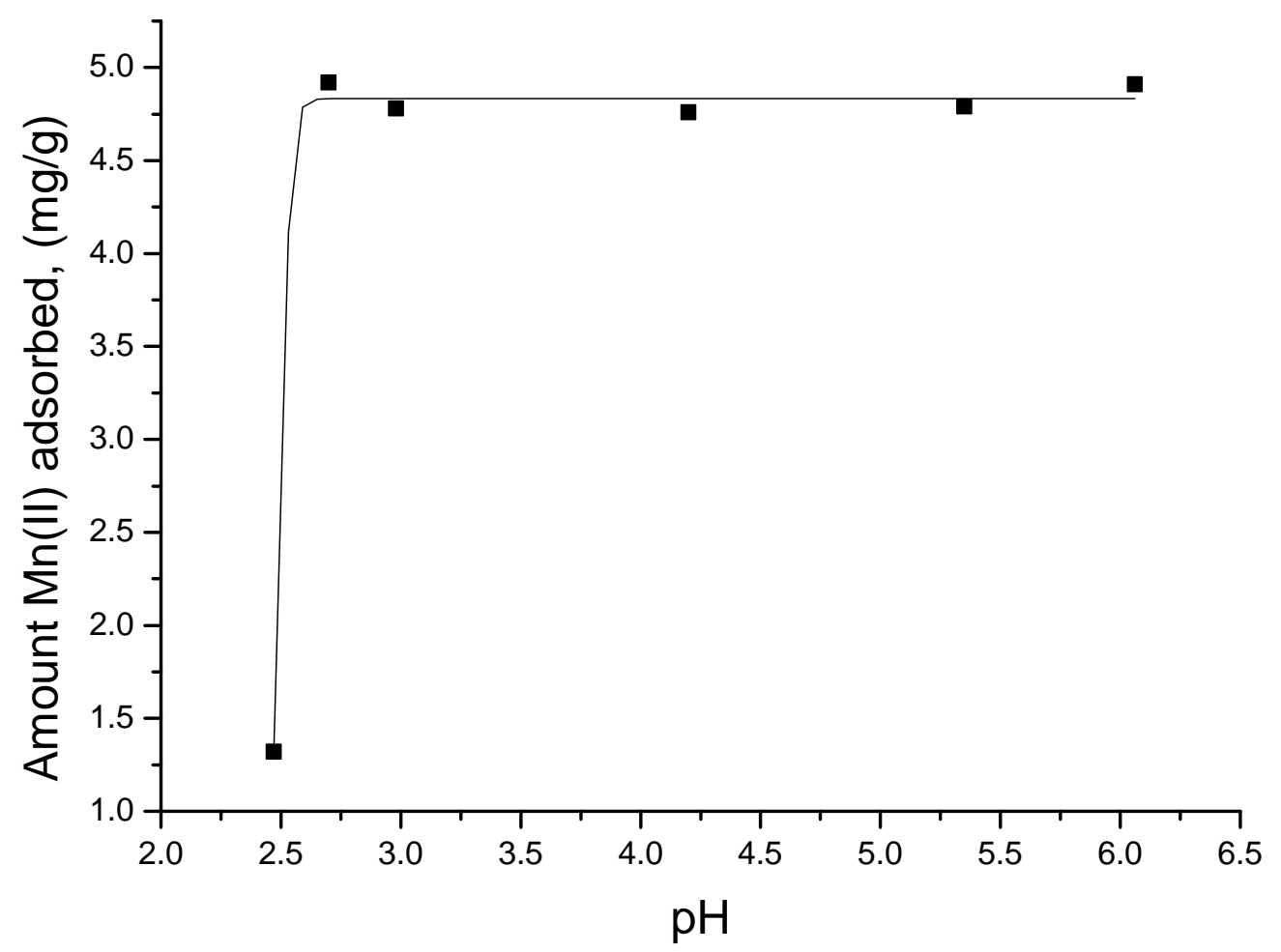

Figure 7. 